\title{
Investigating the role of teacher training of reception teachers in implementing the pre-primary curriculum in Francistown, Botswana
}

\begin{tabular}{|c|c|}
\hline \multicolumn{2}{|c|}{$\begin{array}{l}\text { Authors: } \\
\text { Elisa L. Bawani }{ }^{1,2} \\
\text { Ramashego S.S. Mphahlele }^{3} \text { (D) }\end{array}$} \\
\hline \multicolumn{2}{|c|}{$\begin{array}{l}\text { Affiliations: } \\
{ }^{1} \text { Department of Curriculum } \\
\text { Studies, College of Education, } \\
\text { University of South Africa, } \\
\text { Pretoria, South Africa }\end{array}$} \\
\hline \multicolumn{2}{|c|}{$\begin{array}{l}{ }^{2} \text { Department of Social } \\
\text { Sciences, Faculty of Education, } \\
\text { Mater Spei College, } \\
\text { Francistown, Botswana }\end{array}$} \\
\hline \multicolumn{2}{|c|}{$\begin{array}{l}{ }^{3} \text { Department of Early } \\
\text { Childhood Education, College } \\
\text { of Education, University of } \\
\text { South Africa, Pretoria, } \\
\text { South Africa }\end{array}$} \\
\hline \multicolumn{2}{|c|}{$\begin{array}{l}\text { Corresponding author: } \\
\text { Ramashego Mphahlele, } \\
\text { emphahrs@unisa.ac.za }\end{array}$} \\
\hline \multicolumn{2}{|c|}{$\begin{array}{l}\text { Received: } 19 \text { Jan. } 2021 \\
\text { Accepted: } 23 \text { May } 2020 \\
\text { Published: } 04 \text { Mar. } 2021\end{array}$} \\
\hline \multicolumn{2}{|c|}{$\begin{array}{l}\text { How to cite this article: } \\
\text { Bawani, E.L. \& Mphahlele, } \\
\text { R.S.S., 2021, 'Investigating } \\
\text { the role of teacher training of } \\
\text { reception teachers in } \\
\text { implementing the pre- } \\
\text { primary curriculum in } \\
\text { Francistown, Botswana', } \\
\text { South African Journal of } \\
\text { Childhood Education 11(1), } \\
\text { a882. https://doi.org/ } \\
\text { 10.4102/sajce.v11i1.882 }\end{array}$} \\
\hline \multicolumn{2}{|c|}{$\begin{array}{l}\text { Copyright: } \\
\text { C 2021. The Authors } \\
\text { Licensee: AOSIS. This } \\
\text { is licensed under the } \\
\text { Creative Commons } \\
\text { Attribution License. }\end{array}$} \\
\hline \multicolumn{2}{|l|}{ Read online: } \\
\hline arip & $\begin{array}{l}\text { Scan this QR } \\
\text { code with your } \\
\text { smart phone or } \\
\text { mobile device } \\
\text { to read online. }\end{array}$ \\
\hline
\end{tabular}

\begin{abstract}
Background: Teachers emerge as main role players guiding the process of curriculum implementation across all levels of education. At early childhood development (ECD) level, curriculum implementation is unique, but emphasis on teacher training is essential as it influences teachers' efficacy in promoting holistically developed children. Upon realising the significance of ECD, Botswana effected the Pre-primary Curriculum Framework (PCF) to guide teachers in teaching children.
\end{abstract}

Aim: This article aims to investigate the role of teacher training in implementing the Botswana's PCF in Francistown. Bandura's social cognitive learning theory (SCLT) and Wenger and Wenger-Trayner's communities of practice $(\mathrm{CoP})$ were used as they both advocate for teacher mentoring programmes and partnerships to assist teachers towards effectiveness in curriculum implementation.

Method: Interviews, document analysis and observations were employed as data collection tools.

Results: Despite the support given to teachers towards implementing the Botswana's PCF, they are still faced with challenges such as lack of training, supervision and shortage of materials.

Conclusion: For teachers to effectively implement Botswana's PCF, there is a need for transforming policies on conducting in-service teacher training such as the use of a needs assessment protocol.

Keywords: curriculum framework; curriculum implementation; pre-primary; reception teachers; teacher training.

\section{Introduction}

Teacher training is viewed as fundamental to effective teaching and learning of children. This statement is validated by Darling-Hammond, Hyler and Gardner (2017) who looked into the role played by qualified teachers in the effective implementation of a curriculum. There is considerable evidence on how proper teacher education is a definitive factor for children's effective learning and understanding of concepts even at the earliest stages of learning of early childhood development (ECD). According to Kennedy (2016), teacher training is a necessity for every teacher who wants to join the teaching fraternity. Every year, students enrol at universities and colleges in teacher training programmes to become qualified teachers and when they are employed do inservice training. Darling-Hammond (2017) stated that initial teacher education in-service training is key to the production of highly effective and influential teachers. Concerning ECD, teacher training and its contribution in promoting effective curriculum implementation are inter-related. As suggested by Piasta et al. (2015), this is because, at the level of ECD, children's effective learning and development are mainly determined by the teachers' ability to provide an enabling environment. This is because teachers act as guides and mentors, even though children are expected to experience freedom in learning. This is the basic principle at all levels of learning as suggested by most theories of learning such as Bandura's (1971) social cognitive learning theory (SCLT) and Wenger and Wenger-Trayner's (2015) communities of practice (CoP) employed for this study. These theories are no different from those of other earlier philosophers such as Vygotsky's social constructivism and Piaget's theory of cognitive development in emphasising the significant roles of trained teachers in promotion of children's learning. As suggested by Shabani (2016), one can apply similar contextual references of child learning such as zone of proximal development (ZPD) and scaffolding to adult learning for teacher effectiveness. 
This article aims to report findings on the role of teacher training in promoting teachers' implementation of the pre-primary curriculum framework (PCF) in Francistown, Botswana. The following objectives were determined to examine the different qualifications required for being a reception teacher in Botswana and to identify successes and challenges of Francistown reception-class teachers in implementing the PCF. So, there is the intention to compare what is important for adult learning to support children's learning and to explore the different forms of support offered to teachers in implementing the PCF in Francistown.

\section{Background of the study}

The Botswana PCF was developed by the Department of Curriculum and Evaluation (DCE) under the auspices of the Ministry of Education and Skills Development (MOESD), today referred to as Ministry of Basic Education (MoBE). Botswana's PCF was established in 2012 but became fully functional in 2014 when the government conducted a pilot project for reception classes. It started with 20 pre-primary schools, but the government has since rolled it out to all public pre-primary schools in stages because of the significance ECD holds in the development of children as emphasised in many studies. According to the Botswana National Commission for United Nations Educational, Scientific and Cultural Organization (UNESCO) (2018:19), Botswana boasts of pre-primary or reception classes, which were introduced to about 472 out of 756 primary schools. It is important to note that the stipulated figures relate to 2018 and the number might have increased since then. The PCF was developed as one of the recommendations of the 1994 Revised National Policy on Education (RNPE), which included the need for quality education, universal access to education, equitable education and lifelong learning.

Based on the given affirmation, the PCF is viewed as a reference point that all child caretakers, teachers, parents and other parties can use to guide their daily teaching and learning activities to promote the holistic development of children. One of this framework's requirements is the promotion of professional practice which is the focus of this study. This is because professional development (PD) helps a teacher to interpret the curriculum.

\section{Literature review}

Some scholars such as Schachter, Gerde and Hatton-Bowers (2019) theorise that training of teachers, including those who are teaching ECD, is vital. They, however, warn that certain precautionary measures need to be considered when selecting any PD model because they might offer training that is not beneficial. Some of the defining principles as identified by Schachter et al. (2019) entailed what is to be taught and how it should be taught. This implies that specific training guidelines would help in achieving the expected outcomes in the process of training teachers on the job. Porter et al. (2019) carried out a study at the Science Museum of Boston concerning implementing Engineering topics at ECD level.
Amongst others, the study's data proved that a considerable number of teachers expect to be trained on the job considering the methodologies guiding curriculum implementation to teach the engineering content. The findings also revealed that other external factors of inadequate resources directly affect teachers' efficiency in implementing the curriculum.

In addition, a study by Black (2019) was conducted at one of the United States' private ECD centre to advocate for teacher interactions and enquiry as some of the influential practices in promoting teachers' effectiveness and PD. Employing varied data collection methods such as interviews, formal and informal interactions and participant observations, the study concluded that teacher collaborations would contribute to them being effective in implementing the curriculum as they would reflect, critique, and correct one another during their interactions, thereby increasing their understanding of some curriculum concepts and other teaching-related issues.

The aforementioned studies suggest that countries that highly regard teacher training or PD as a basic tenet, benefit from a teaching workforce that is knowledgeable and able to impart the desired teaching and learning outcomes to the children. This is what can be referred to as sustainable education development because even though PD may be capital intensive, venturing into a valuable one as suggested by Schachter et al. (2019), would result in highly effective teachers who are able to share their acquired skills with the children and co-workers, which would save the country from having overly dependent people as they would be empowered. Given the fact that Botswana is a middle-income earning economy, teacher training comes as a requirement that all teachers, including ECD teachers, be well trained for the purpose of sustainable economic development. Pianta, Downer and Hamre (2016:119), in explaining what quality ECD is, identify four attributes, namely 'length of training or teachers' qualifications, classroom environment, teacherstudent interactions and aggregate indices ranging from playground equipment to activities involving staff, children or parents'. In their study, Pianta et al. (2016) emphasise that the effectiveness of teachers in implementing any curricular activities depends on PD.

\section{Theoretical framework}

The lenses through which the phenomenon was viewed were Bandura's SCLT and Wenger and Wenger-Trayner's (2015) CoP. These theoretical principles were found to be complementary and emphasising on teacher developmental roles. SCLT posits that learning occurs through observation, imitation and modelling (Bandura 1971), whilst CoP advocates for the existence of partnerships to share knowledge and ideas on how best teachers can be assisted and even help each other to develop professionally (Wenger \& WengerTrayner 2015). In both theories, there is an emphasis on employment of mentors for teachers to be efficient.

Bandura's SCLT theory suggests that human learning can be optimised through providing training for the subjects to cope 
with any impediments they could be facing (Bandura 1994). Bandura's theory suggests the following strategies to be applied to effect change: planning, illustrations or experiments, self-control and assessment procedures. This is understood to mean that in the aim to assist teacher to be effective in implementing the curriculum, the processes of modelling, imitation and observations could be established, in the same way as children learn (Shabani 2016). Shabani (2016) posited that teachers' PD is applicable to other behaviourist and constructivism theories such as Vygotsky's ZPD, scaffolding, mentoring and enquiry. This is perceived to denote adult learning as being similar to children's teaching and learning, hence the same strategies could be applied.

Different studies have been undertaken to position the significance of teachers' PD such as a study by Dossett et al. (2019), which found out that one of Tennessee schools employed Bandura's SCLT to enquire about Agriculture teachers' effectiveness in teaching Mathematics skills. Amongst others, the study revealed that without PD in Maths skills, it would be difficult for teachers to effectively teach Agriculture as part of infusing Science, Technology, Engineering and Mathematics (STEM) development. Abreh (2018) also carried out an exploratory study in Ghana about the insights of leaders from different departments regarding the impact of teachers' involvement in ongoing PD activities in the teaching of Science and Mathematics. The study showed that leaders supported the idea of continuing PD (CPD) because they believed it influence teachers' effectiveness in teaching the concerned subjects. It also emphasised that leaders have a role in influencing CPD activities.

Against this backdrop, it is evident that to implement the curriculum, teachers need to be relevantly trained to be able to apply differentiated teaching (DT) approaches and to cater for all children's needs. According to Mavidou and Kakana (2019), DT relates to the teacher being able to incorporate varied teaching methodologies into their pedagogy. This is because teachers are regarded as the main drivers in curriculum implementation; hence, they need to be fully trained to be effective in their work. The Department of Curriculum Development and Evaluation (DCDE) (2012b:13) delineated the teaching practices that would support ECD children's learning being 'child-centred, integrated, developmentally appropriate and monitoring and evaluation systems through action research'. This suggests that ECD teachers as role models in implementing the curriculum are called to be trained to apply the stated strategies to promote children's learning, and through proper training that could be ascertained.

Turning now to CoP, Farnsworth, Kleanthous and WengerTrayner (2016) suggested that effective learning takes place through social interactions. This is assumed to mean that all sociocultural and historical contexts have a direct influence on effective teaching and learning. The main proposition of CoP is that all the perspectives of teaching and learning should be considered in combination for the promotion of teachers' effectiveness in implementing the curriculum. These factors would include, amongst others, skills development through initial and ongoing training, provision of relevant and adequate teaching and learning resources and children's involvement in learning activities. Applying both SCLT and CoP provides an enabling teaching and learning environment through equipping teachers with all the necessary skills. The assumption is that this would enable teachers to be effective in implementing the PCF.

Vrieling, Van den Beemt and De Laat (2016) affirmed the given proposition. In their study, they noted that teaching as a social activity can effectively be achieved through the employment of active, interactive and procedural channels. These would involve interconnections such as proper communication channels, availing teaching and learning materials, sharing of these materials, and working, learning or playing together.

According to MOESD (2012), the Botswana PCF is a guide aimed at assisting teachers to plan activities for the holistic development of children. Therefore, it calls for teachers to be professionally trained to be able to cascade it to others. This is because the guide provides details and suggestions on how teachers are expected to implement it and includes teachers' guides and any other support materials. For instance, it stipulates suggested activities relevant for preschool children's age categories and provided information on the learning support resources needed. This is intended to enable the teacher to make an informed decision on how to approach different learning areas and children's activities to promote effective learning and development of skills. Drawing from both Bandura and Wenger and WengerTrayner's arguments, it is fitting to conclude that the two theories recognise that an enabling environment is a necessity for the promotion of effective implementation of the curriculum, the most important element being welltrained teachers. This suggests that united efforts in assisting teachers to promote effectiveness in their daily usage of the PCF are valued and feasible.

The two theories of SCLT and CoP aided in formulating the research design and the selection of the data collection tools. The combination of the two theories would act as a catalyst in helping towards understanding the teachers' PD because CoP allows for teachers to learn about appropriate teaching methods collaboratively whilst SCLT perspective would enable them to observe and apply good practice. So, the interview questions asked, studied documents and observed variables concentrated on the following components:

- if teachers are satisfied with the pre- and in-service training to deliver the PCF

- knowing the successes and challenges of Francistown, Botswana reception teachers in implementing the PCF to support children's learning 
- reflecting on the importance of teacher effectiveness and holistic development of children in implementing the PCF

- identifying teachers' understanding of children's role in participating in the implementation of the PCF.

\section{Research design}

The research design involves a plan on how a study is to be conducted (Tredoux \& Smith 2010). An interpretive phenomenological research design helped in shaping the focus of this study. This design is employed in most qualitative research studies. According to Yüksel and Yıldırım (2015), a phenomenological research design connects with a range of research paradigms such as constructivism and critical reviews. The phenomenological research design was appropriate for this study as its fundamental principle is to understand a phenomenon from the participants' lived experiences. The views and observations of ECD teachers, their school principals and education officers were interpreted to construct the meaning of what was assumed to be occurring in the process of implementing the PCF.

Based on Alase's (2017) views on the application of interpretative phenomenological approach (IPA), the authors concur that the interpretive paradigm assists in conducting an open-minded analysis about the participants' narratives. In this case, the social and interactive component of IPA, as described by Tuffour (2017), emphasises that the design calls for researchers to study a phenomenon thoroughly and objectively within given time constraints. This involves adopting a flexible approach to get to the details of the participants' experiences rather than making assumptions. It also emphasises that the researchers focus on the teachers and education officers' views as they implement the PCF in their natural settings. The relevance of the IPA approach in this study is driven by the main aim that is to investigate the role of teacher training in promoting teachers' effectiveness in implementing the PCF in Francistown, Botswana, from the perspectives of reception class practitioners, namely teachers and education officers. The following questions were employed to guide the study.

\section{Research questions}

The following research questions were formulated to assist in selecting relevant research methods:

- What are the different qualifications of reception teachers who are implementing the PCF in Francistown, Botswana?

- What are teachers' perceptions of successes and challenges in implementing the PCF in Francistown, Botswana?

- What form of support is offered to reception teachers implementing the PCF in Francistown, Botswana?

\section{Study site and sample}

The sample was collected from three government preprimary schools, three reception teachers, two principals and two education officers involved in implementing the PCF. The two education officers were the Principal Education Officer (PEO) from the Regional Education Office (REO) and Principal Education Secretary from Local Government (LG), which falls under Ministry of Local Government and Rural Development (MLGRD). All the participants were purposefully selected by being directly involved in the implementation of the PCF. Teachers were selected through the employment of purposive random sampling as in some cases there were more than two teachers in each school. The process of purposive random sampling involved listing all the names of teachers according to numbers as if conducting a raffle and putting them in a container. Then the names were randomly picked, two from each school. This was conducted to avoid issues of conflict of interest in selecting the teachers.

\section{Data collection methods}

The main data collection methods employed were face-toface interviews, document study and class observations to investigate the views and experiences of teachers in implementing the Botswana PCF. As the study was performed using IPA, the data were collected from a qualitative perspective of spending considerable time in the field interacting with the participants. The three data collection methods served to validate the information obtained from the participants.

\section{Data analysis}

Phenomenological data analysis was used to explore the role of teacher training on the effectiveness of reception teachers in implementing the pre-primary curriculum. This involved making meaning of the experiences and views shared by participants but being aware of personal bias, as advised by Sutton and Austin (2015). The following steps were taken in the data preparation: transcribing, coding and generation of themes or categorisation. Data transcription involved making sense of the audio and written interviews through transferring them verbatim to paper to make a comprehensive report. The transcribed data were then cleaned and related information was grouped according to themes or categories of the same meaning. This was carried out manually through Microsoft 'Review' and 'Add comment' tool. The researchers agreed to use this tool for purposes of having full ownership and understanding of all the collected data. For the promotion of rigour during data analysis procedures, a professional co-coder was engaged to conduct the vetting process on themes that emerged. The vetting process involved adopting themes that emerged and making suggestions on those to be included. According to Lombard, Snyder-Duch and Bracken (2002), the exercise of co-coding and vetting is common amongst researchers employing content analysis. It involves developing a cordial relationship between a team of researchers who individually code the data, then exchange ideas for purposes of accepting that which is relevant for their research as part of promoting rigour. The same was carried out for triangulation between interview data in comparison to the data collected from 
observations and document analysis. The following subsection presents the findings.

\section{Ethical considerations}

The low-risk application was reviewed by the Ethics Review Committee on 14 November 2018 in compliance with the University of South Africa Policy on Research Ethics and Standard Operating Procedure on Research Ethics Risk Assessment (Ethical Clearance number: 2018/11/14/ $58532390 / 70 / \mathrm{MC})$. All the participants and institutions are concealed for ethical considerations.

To adhere with proper research procedures, the authors applied to the Ministry of Basic Education Regional Education Office requesting permission to conduct research within Francistown public pre-primary schools. Upon receiving permission, the authors sought consent from the principal of each preschool identified, the teachers and education officers. Before each interview session, class observation or request for documents, participants were requested to sign a form acknowledging their consent to participate in the study. Before signing the consent forms, the participants were provided with the information sheet that outlined the purpose, ethical implications and what is expected from them in relation to the study. The informed consent letter stated that participation in the study was voluntary and they were free to withdraw, not answer any questions or surrender any documents if they felt uncomfortable with disclosing any information required from them. Pseudonyms were used to protect the anonymity of the participants. To identify the participants in the text, the pseudonyms were structured according to the order in which they were interviewed, gender, profession and age. A presentation of the processes used in the data analysis is as follows:

- Teacher 1, from School 1, female, 28 years old - T1S1F28

- Teacher 2, from School 2, female, 30 years old - T2S2F30

- Teacher 3, from School 3, female, 39 years old - T3S3F39

- Principal 1, from School 1, male, 56 years old - P1S1M56

- Principal 2, from School 2, female, 45 years old - P2S2F45

- Principal Education Officer, male, 53 years old - PEOM53

- Principal Education Secretary, female, 52 years old PESF52

After ascertaining the consent of participants through appending of signatures, different appointments for meetings were set and data were collected accordingly.

\section{Results}

Under this section, data are presented on how participants viewed and experienced the role of teacher training on their effectiveness in implementing the Botswana PCF in Francistown. Data presentations were made considering the data collected from interviews as correlated with that of studied documents and classroom observations as per the views of teachers, SPs and EOS. The interconnection between the themes and the objectives is presented in Table 1.
TABLE 1: Presentation of the study's objectives and emerged themes.

\begin{tabular}{|c|c|}
\hline Study's objectives & Emergent themes \\
\hline $\begin{array}{l}\text { To examine teachers' different } \\
\text { qualifications in promoting effective } \\
\text { implementation of the PCF in Francistown }\end{array}$ & = \\
\hline $\begin{array}{l}\text { To identify successes and challenges of } \\
\text { Francistown reception-class teachers in } \\
\text { implementing the PCF to support } \\
\text { children's learning }\end{array}$ & $\begin{array}{l}\text { Successful teacher experiences in } \\
\text { implementing the PCF and challenges } \\
\text { faced by teachers in implementing } \\
\text { the PCF }\end{array}$ \\
\hline $\begin{array}{l}\text { To explore the different forms of support } \\
\text { offered to teachers in implementing the } \\
\text { PCF in Francistown }\end{array}$ & $\begin{array}{l}\text { Different forms of support offered to } \\
\text { teachers to promote effectiveness in } \\
\text { implementing the PCF }\end{array}$ \\
\hline
\end{tabular}

Source: Adapted from Mphahlele, R.S.S., 2018, 'Information communication technologies as a aupport mechanism for learners experiencing reading difficulties in full-service schools', PhD thesis, University of South Africa.

PCF, pre-primary curriculum framework.

As illustrated in Table 1, from the study's objectives, three themes emerged upon analysis of collected data.

\section{Theme 1: Teachers' different qualifications and how it affects effective implementation of the Pre-primary Curriculum Framework}

In addressing the question of teachers' qualifications, the participants detailed on the different forms of training, dosage and methods applied, which could be crossreferenced with the literature and chosen theoretical model. On the types of training received, all teachers indicated that they were trained through either pre or in-service towards the implementation of the PCF. This was confirmed by the information in the records provided by the school principals: 'I have been trained for breakthrough and not for reception class ... but I was lucky to go for further training and be the first person to go to the workshop' (T2). Another teacher, T1, reported that she started with an advanced certificate in ECD, later upgraded to Diploma and attended a one-week workshop which contributed to her better understanding in the implementation of the PCF. By these, teachers emphasised the existing correlation between PD either through pre and in-service training workshop they attended and their effectiveness in implementing the PCF. This is what is confirmed in literature such as Kennedy (2016) that teacher training qualifies teachers to practice and through the SCLT and $\mathrm{CoP}$ theoretical model, they were able to form teacher collaborations, observing and applying what has been learnt. This illustrates that in the host country, teachers are hired based on certain qualifications starting from certificate level.

Relating to dosages they received on training, all teachers emphasised that the in-service training had contributed towards their being effective in implementing the PCF. T1 alluded to the fact that '... they taught us everything. I learnt a lot, I learned more than what I did at tertiary', suggesting that the in-service training workshop she underwent had addressed all her teaching and learning needs for effective implementation of the PCF. T3 affirmed this when she said, '... they explained how to prepare a lesson plan and teach according to it'. Furthermore, T3 said:

'[T]hey taught us how to write, plan, and update the weekly schedule. They trained us on the changes that had been made concerning the old curriculum; scheming and lesson planning.' (Teacher 3, school 3, female, 39 years old) 
The given findings corroborated the PEO's and the SP's assertions that workshops were conducted to train the teachers on how to effectively implement the PCF. The PEO reported that 'we train them on different things, on the curriculum framework ... show them how to handle SEN [special education needs] learners, we look at the whole curriculum ...' Furthermore, P2 cited that 'region is always much willing to assist by conducting workshops'. These findings are in agreement with findings of Abreh (2018) and Dossett et al. (2019), which showed that teachers' PD positively influences effectiveness in implementing any given curriculum. It also confirms the SCLT perspective in the sense that if teachers are well trained, they become good role models in implementing the curriculum.

For triangulation purposes, the interview results were correlated with that of the written documents and class observations. The studied documents included the PCF, the scheme of work and lesson plan booklets. They proved that indeed the teachers were able to scheme and prepare lesson plans as per the expected standard of the PCF. However, it was learnt that there was a limited number of copies of the PCF as was shared amongst all classes. This explained why there was some missing information in some documents such as the record of work done and some lesson plans. The given findings prompted for further probing into teachers' efficacy relating to the in-service training they had received. Although teachers initially indicated their satisfaction relating to the conducted workshop, they worried about how the training was conducted. For example, T2 said, 'When it comes to implementing it is not easy.' Furthermore, T1 stated that '... with the moral and spiritual objective, it is very difficult to teach children because we see that nowadays people believe in different things'. The given statement suggests that there might be existing challenges on the part of teachers to effectively address some topics in the PCF even though they had previously reported to having been satisfied with the training workshop they attended. This critique was concluded to be relating to training because upon studying the training workshop programme, it was realised that it was conducted only once, and the topics covered were suggested by the PEOs. According to UNESCO (2015), it is advisable to train the curriculum implementers, and in this case, reception teachers, considering their unique challenges and backgrounds rather than deciding topics for them.

The given findings are also understood to suggest that teachers' in-service training was somehow centralised and followed a top-bottom approach. When P1 said, 'The training is done by them, and it is their duty', it is implied that school principals were somehow detached from implementation and training in the PCF. P1 was referring to the PEOs when he said 'them'. This denotes that the training of teachers was perceived as the sole mandate of the PEOs, who, according to the findings, were also not qualified for ECD and PCF training. The data also revealed that the PEOs are not directly engaged with teachers on a regular basis. Their mandate was reported as to conduct routine inspections at the assigned schools and assist with organising in-service training workshops for the teachers. The assumption is that training was supposed to be conducted at least through the engagement of school managers. A possible explanation for these results may be the lack of instructional leadership for ECD at school level. Bellibas and Liu (2017) suggested that there is a correlation between school leadership and teacher PD. This is because the principals could help direct PEOs in creating clear training guidelines, suggesting content and influence trainers. It is important to caution that these findings cannot be extrapolated to all schools implementing the PCF in Francistown and other parts of the country as only three schools were visited.

A follow up with classroom observations revealed another interesting aspect relating to the theme on training as it appeared that teachers inadequately infused the play-based learning methodology to implement the PCF. For example, T3 made the children sing the 'Body parts' song only at the end of the lesson. The observations made concerning T3's teaching approach were believed to be tantamount to lecturing. Contrary to what was observed, research shows that children learn best when they apply all their senses of touch, smell, listening, speaking and hearing to understand concepts. The DCDE (2012a) clearly emphasised that play should be employed as the main methodology in teaching children as it promotes an opportunity for children to apply all their senses. This, together with the proposition based on one of the prominent founders of play-based learning in ECD, Friedriech Froebel, children effectively learn through adventure and exploration of their environment (Aljarrah 2017).

Although traditionally, there has been emphasis on the value of play and its contribution to children's learning, some scholars such as Pyle, Prioletta and Poliszczuk (2018) argued that play can be applied in different ways ranging from free to being structured. Free play involving children playing as they like whilst being structured whereby teachers lead children towards learning activities (Clark 2020). Therefore, a possible explanation to what transpired during that class observation can be that maybe the strategy that the teacher employed was rather inadequate as it tended to limit children's exploratory skills as the teacher seemed to dominate both discussions and singing. In this scenario, one can safely conclude that the teacher's role in setting up and guiding activities did not necessarily provoke children's learning because of limited play activities. This is because as the children play, they learn without even realising that learning is taking place as suggested by Yilmaz and Pala (2019). According to Lopez (2018), play is one of the most important ways in which young children gain essential knowledge and skills.

The given findings motivated interest to interrogate the school supervisors and the REO on how teacher training towards implementation of the PCF was conducted. P1 said, 'I am not familiar with the programme ... the training is done by them, it's their duty'. The PEO echoed the same 
sentiments that, 'I have been nominated to babysit the programme'. This suggests that they were not trained on the programme and so would not able to satisfactorily assist teachers to implement the PCF. Contrary to the given findings, Zahnd et al. (2017) suggested that supervisors should be more knowledgeable at least with a basic understanding of curriculum implementation issues they are assigned with.

Concerning the use of training guidelines, Lam and Tsui (2014) indicated that these are powerful tools that should be used to empower teachers on curriculum efficacy. Furthermore, Úcar (2013) suggested that teachers are at liberty to implement the curriculum the way they understand it. The findings of the study proved that teachers were provided with in-service training and that guidelines were available although directed and administered by PEOs. When the PEO said, ' ... there isn't a guideline for training ... we look at the curriculum framework and say these are the most important things that we can assist teachers on', it was a clear indication that the REO did not have a formal policy in place guiding ECD teachers' in-service training. Upon studying the training workshop programme, it was found out that it covered content that the teachers did not raise complaints on except for scheming and lesson planning.

The given findings suggest a contradiction between the teachers and the PEO as it appeared that content was suggested by PEOs. Given the CoP theory and UNESCO's (2015) suggestion, engaging into a joint effort between school supervisors, teachers and PEOs might have been better. Further probing revealed that only one training workshop had been conducted. Contrary to the participants' claim that there were no training guidelines, a closer look at the programme that guided the conducted training revealed that some specific protocols were realised. The programme contained expected learning outcomes and the content, duration and venue of the workshop.

Another implication of this can be that teachers' in-service training was somehow centralised and followed a top-bottom approach. This was realised when P1 said, 'The training is done by them, and it is their duty'. P1 was referring to the PEOs. This denotes that the training of teachers was perceived as the sole mandate of the PEOs who, according to the revelations, were not qualified for ECD and to provide training on PCF. Also, it was found that they were not directly engaged with teachers on a regular basis. The PEOs' major mandate is to conduct routine inspections at the assigned schools and not train the teachers. The assumption is that training was supposed to be conducted at least through the school managers, as suggested by Bellibas and Liu (2017) arguing from the instructional leadership perspective that SPs could be engaged as part of formulating clear training guidelines and content for teacher trainers to achieve their role to promote teachers' effectiveness in implementing the curriculum.
The findings of this study demonstrated that indeed teachers believed that teacher training is vital as a tool to enhance professional insight and teacher confidence in implementing the PCF regardless of the perceived inadequacy in meeting their curriculum needs. When T3 reported that 'It was an eye-opener', and T1 said, 'I learnt more than what I did at tertiary ...' it validated that indeed teachers had valued training as it significantly improved their effectiveness. This confirms that there is a correlation between the process of teacher training and effective curriculum implementation. This is because as indicated by previous studies such as Dossett et al. (2019), it was proved that PD improved teachers' effectiveness.

\section{Theme 2: Successes and challenges experienced in implementing the pre-primary curriculum framework}

From the given presentation of findings, even though teachers were able to implement the PCF because of pre and in-service training they had received, they were faced with some challenges. The success stories they shared in implementing the PCF are addressed under theme 3 on the different forms of support that enabled them to effectively work.

Concerning challenges faced by teachers in implementing the PCF, unavailability of learning resources and limited spaces for play-based learning were major challenges that were reported to be hindering effective implementation of the PCF. Other challenges included perceived inadequate teacher training and lack of parental support. Consistent with the SCLT and CoP theories, it means that with limited resources, they would not be able to assist children to understand some abstract ideas. This is suggested by Hivner et al. (2019) in relation to the SCLT, which advocates for teachers to act as role models. So, with lack of or unavailability of learning materials, it would prove difficult for teachers to model behaviours as expected to be learnt by the children. For example, T2 said, '... by reading I don't simply mean like reading sentences or what, they don't have picture books, so that is the problem that I face here'. Two possible explanations for this might be that teachers were unable to model behaviour for reading as there were either no teaching aids available for that or maybe there was inherent lack of adequate training towards being effective in implementing the PCF as was assumed in theme one. According to Omaga and Alieto (2019), at ECD level, play methodology could be employed as the basic foundation for early literacy. In conjunction with $\mathrm{CoP}$ that advocates for school and teacher collaborations, teachers could then work towards sharing skills and ideas on how to apply the different play strategies. The data reported here appear to support the assumption that the teachers were faced with challenges emanating from either lack of proper training or inadequacy of resources, because of insufficient support systems from their schools and REO.

It was realised that all seven participants agreed that teaching and learning resources influenced teachers in implementing the PCF. A lack of funding was reported as one of the causes 
of the shortage of teaching and learning materials. This was alluded to by the PES when she reported that 'We are no longer having funds for these materials ... we didn't plan for it ... we didn't budget for it this year'. This was confirmed by the PEO saying, 'there are not enough resources; some schools don't have enough materials'. The teachers also corroborated this by saying, 'We don't have the resources or learning materials', (T2) and T3 who said, 'but the truth is there is nothing ... no resources or things or stationery'. According to The World Bank (2019), all Botswana government reception classes are funded by two ministries, viz., MLGRD that is responsible for provision of infrastructure and learning materials with exception for textbooks, whilst MOBE provides teacher training and welfare teaching services in the form of curriculum development and implementation, teacher training, employment and salary payments. It was learnt that in the issue relating to resources provision, there seemed to be a slippage as to understanding whose mandate it was to provide certain teaching and learning resources. This is because the PES was confident about the materials they were expected to provide to schools as she said, 'we are mandated to provide the outdoor teaching and learning material, school furniture and teachers' furniture, the health and safety materials'. When the PEO said, 'we provide the teaching staff, while the local government provides the teaching materials', it appeared rather contradictory to what was suggested by the PES. This discrepancy could be attributed to perceived lack of training on the part of supervisors as already mentioned in Theme 1. This is because the findings from the interviews with the PES concerning the distribution of the specific learning resources revealed that they had been equally distributed to all the preschools in the region. This information was corroborated with an illustration in the City of Francistown Council (2018) document.

Abroampa's (2018) study investigated the differential impact of learning materials on effective implementation of any curriculum and concluded that availability of resources enables teachers to be efficient whilst unavailability compels them to improvise in order to meet the required curriculum outcomes. Abroampa (2018) advocated for the provision of relevant teaching and learning resources as part of the support needed in promoting effective curriculum development and implementation. Consistent with this study, the PES reported that 'I think teaching and learning are difficult', and the PEO who said, 'I found that these bikes were in the store-room and children had never used them because there were not enough ...'. Still, on the same issue, the PEO said, 'teachers use small crayons which easily break ... with small children, with small fingers, they can't handle small things'. The given findings were provided in respect of a question relating to the significance of resources to the teachers' effectiveness in implementing the PCF. The responses indicate that without relevant teaching and learning resources, the teachers would be hindered from effectively implementing the PCF goals and, by extension, this would impair on the intended holistic development of the children.
Another challenge observed in this research was the timetable factor. $\mathrm{T} 2$ indicated that there seemed to be a 'time limit for the lesson'. However, there seemed to be incoherence with this sentiment because as espoused in the DCDE (2012b), there is a suggestion for teachers to practice flexibility in implementing daily plans to ensure that each child's unique learning needs are catered to. This principle is supported by the vast literature of Aiono, McLaughlin and Riley (2019) that at ECD level of education, a flexible timetable can be adopted as one of the best remedies for challenges of time. So, the seeming discrepancy portrayed by the teacher could be attributed to insinuation that maybe the teachers were not conversant with time management skills or the PCF principles, hence the researchers inferred that there was inadequate in-service training on their part although the other two respondent teachers did not comment on the issue.

Lack of school and regional education support was cited as another impediment that teachers faced and it has already been discussed in Themes 1 and 2. So when T2 reported that 'They are not supportive when it comes to resources, maybe there is lack of knowledge', relating to school managers, and 'I have never met anyone from the region' referring to the regional support, this could be interpreted as an indication that the teacher was faced with some challenges in implementing the PCF such as lack of learning and teaching resources and relevant support was not offered.

\section{Theme 3: Different forms of support offered to teachers to promote effectiveness in implementing the Pre-primary Curriculum Framework}

The findings of this study indicate that different support contexts emanating from REO, LG and parents were essential in supporting effective implementation of the PCF. Five out of seven participants specified that the LG was responsible for offering some teaching and learning materials, but no clarity was offered on provision of some resources such as stationery and textbooks. To validate the findings as to LG's mandate, the researchers reviewed some documents entitled 'Reception Class Materials Distribution for 2017 to 2018'. The document revealed that indeed LG was responsible for providing all the outdoor and indoor learning equipment and materials such as swings, trampolines and bunk beds. This was further corroborated by the PES by saying 'I provide resources - outdoor teaching and indoor learning resources and maintaining facilities'. Another document reviewed was the MOESD (2015b). The document stipulates the preprimary school teaching and learning resources to be dispatched. Information in this document revealed that there were some legitimate expectations concerning the provision of resources on the part of LG to public preschools for the implementation of the PCF. The protocols on the assumed provision of teaching and learning resources were meant to minimise inequalities in available resources and to promote the quality of learning in all the schools (MOESD 2015b). 
The observations made by this study show that indeed there was a noticeable availability of some outdoor teaching and learning resources although not to a satisfactory level as participants indicated. Some of the outdoor resources such as the trampoline were found indoors and reason advanced for this was that there was no space where they could be erected.

The findings also revealed that parents were involved in supporting their children. This is supported by literature provided by Morrison, Story and Zhang (2015) who emphasise that parents have a role to play to contribute positive results in the educational dispensation of their children through partnering with schools. P2 said, 'We encourage the schools to involve parents to help them', and T1 said, 'The parents are the ones who buy reams of paper so that they scribble on them'. The given findings show that indeed some challenges occurring in schools could be solved through parental involvement. The PEO's comment that '... they were adopted and now the second class is flourishing as far as equipment is concerned', suggests that a fruitful relationship with parents results in an effective curriculum implementation. The PEO elaborated that the parents had assisted the government by making donations towards the building of another classroom at a different school, which assisted teachers in implementing the PCF rather than worrying about infrastructural impediments.

Conversely, two participants indicated that lack of parental support hindered the achievement of their goals of meeting the PCF's intended objectives. T3 said that 'Parents are very reluctant to help ...', and T2 shared the same sentiments when she reported that, 'Parents always promise but they don't pay'. These findings suggest the opposing views towards parental support. To interpret this data, the researcher delved into the contextual backgrounds of other countries to envisage if reception year is free and whether parents are expected to contribute. According to UNICEF's (2019) review on the state of ECD funding, the most developed countries spend equitably towards development and improvement of ECD. This proposition is substantiated by Nel (2016) who posited that in Sub-Saharan Africa, South Africa, as one of the leading economies, funds Grade $\mathrm{R}$ level according to the differing economic situations of either the centres or the children. This implies that ECD funding in South Africa is geared towards impoverished areas to be able to purchase some teaching and learning materials and improvement of infrastructure. In Asia, Lao People's Republic, reported as one of the fastest growing middleincome economies, is purported to be fully sponsoring pre-primary education ranging from teacher remunerations and all other materials. In the United States of America, the United States Federal regime is reported to finance all Head Start programmes with about four-fifths of the total cost if those receiving grants can cover themselves with the remaining amount. It is further stated that the remaining balance can either be worked for, paid in monetary forms or applicants can apply for an exemption to be renounced if they cannot manage to pay for themselves (UNICEF 2019).
The given observation may be explained in terms of the fact that different socio-economic backgrounds determine whether parents can afford to support the schools or not as suggested by Du Plessis and Mestry (2019). It was previously indicated that this study was conducted within an environment of mixed economic backgrounds; hence, some parents could afford to assist whilst others could not. The findings also show that parental support was a result of team effort that existed within the Francistown region as a unit. As espoused within the CoP and SCLT theories, involvement of all stakeholders aid in the promotion of effective curriculum implementation. These theoretical underpinnings were echoed within the participants' views as they recalled incidents of parental support that were reported to have been attained through team effort and mentoring. As the PEO said:

'To the parents I would say ... please give [to] this school, they don't have anything ... we shall be taking teachers around schools to see, to benchmark best practice ... we also encourage them that if you come up with anything that you feel should be shared, please say it ... and then we also we have a group ..., WhatsApp group so we share ...' (Principal education officer, male, 53 years old)

This is a great example for SCLT and COP approach and a clear indication that team effort would assist teachers to effectively implement the PCF.

Another challenge that was implied was the seemingly lack of effective supervision from both the school managers and the REO. Responding to the question on supervision as one of the support initiatives at school level, T3 detailed that:

' $[W]$ hen it comes to them now, it is a difficult thing, because they will say we were not trained for this thing, we are just babysitting. So as times goes on that is when maybe there will be officers who are suitable for this preschool classes, who can be can able to assist you well.' (Teacher 3, school 3, female, 39 years old)

A possible explanation for these results may be inadequacy on the part of the school-based supervisors. They were interpreted as not being helpful because of lack of training. This contradicts the argument posited by Ozkan (2016) that supervision intended for teachers is aimed at providing positive and constructive feedback rather than a fault-finding exercise as some may presume. The PEO confirmed these results by saying:

'Actually I am not an inspector, I am an officer, an in-service and training officer but of course due to lack of power, manpower, I have been nominated to babysit the programme. So, I am also learning, though I do these inspections.' (Principal education officer, male, 53 years old)

The sentiments shared by the PEO revealed that somehow there might have been no set standard procedures for teachers' PD in relation to implementing the PCF at school level and this could impact their effectiveness. This is because, as suggested by Zahnd et al. (2017), effective supervision emanates from the utilisation of training guidelines oftentimes informed by supervisors. This was posing a challenge to the MoBE and REO to consider involving immediate supervisors in the 
implementation of the PCF. What was happening on the ground seemed to contradict Sarikaya and Erdogan's (2016) assertion that school managers as immediate supervisors should be involved in improving teachers' PD.

Even though the given findings are not so encouraging, P2 informed the author that regardless of the perceived lack of training towards implementation of the PCF and pre-primary classes on their part, class observations and other forms of supervisory support were being offered and proved fruitful as teachers always complied with suggestions made from their office. It was reported that the Head of Department (HOD) applied her general knowledge of teaching the lower primary classes such as the designing and making use of teaching aids to give advice to teachers. This information was confirmed when T1 said:

'When they visit, especially the HOD, advises on how we can make our class to be relevant and also helps us with charts if they are not enough to make the classes look interesting to children.' (Teacher 1, school 1, female, 28 years old)

This can be viewed as a positive approach on the part of this HOD because immediate managers work closely with teachers in coordinating all school activities ranging from supervising curriculum development and implementation activities, and organising teaching and learning resources to implementing procedures for staff development. Therefore, supervisors need to be delegated with the responsibility for coordinating and supporting curriculum development activities in their respective schools.

\section{Discussion of the main findings}

This study focused on investigating the role of teacher training in promoting teachers' effectiveness in implementing the PCF in Francistown, Botswana. The major findings of the study were analysed using IPA, meaning that themes emerged during the coding process. The study's objectives were related to the emergent themes to provide a comprehensive understanding of the study's findings.

\section{Experiences and views of teachers' training levels on the implementation of the pre-primary curriculum framework}

From the responses of all the three teacher participants, it was realised that they were using the PCF as an initiative newly introduced by the government to direct them. The answers given showed that teachers applied it in their daily teaching and learning activities as a guiding tool to implementing the PCF. The responses that they shared reflected on the two theories SCLT and CoP. This contention is illustrated by some of the submissions that were made such as when the PEO hinted that they encouraged parental involvement through 'adopt a school' initiative and requesting for some donations. This was confirmed by some teachers even though some reported otherwise. Another example involved a scenario whereby teachers were encouraged to form partnerships and benchmark best practices from each other. These examples provided a relevant example of manifestation of both the SCLT and CoP. CoP theory calls for efficient partnerships in ensuring that teachers' teaching needs are met through teamwork.

SCLT advocates for the provision of an enabling environment for teachers to be effective role models in teaching and learning. This proposition is supported by the data that related to provision of teaching and learning resources as expressed by the PES although there was serious contention on whose mandate it was for their availability. What could be drawn from these findings was that there appeared to have been a gap that existed on whose mandate it was between MoBE and MLGRD as to who should provide stationery to reception classes. What was found to be even more interesting was that the two offices were aware of their duties, but a disparity observed on who was to provide stationery for reception classes.

Another SCLT feature that could be associated with this study's findings was the issue of teacher training, that a certain effort was made to train teachers towards implementation of the PCF. Training, however limited or fragmentary, was aimed at enabling teachers to be better role models in implementing the PCF. This was displayed by T1 when she alluded to the fact that it 'opened her eyes'. By 'opening her eyes', this can be understood as that the teacher indirectly suggesting that she was being a better role model in implementing the PCF because of training she received. So, considering that the PCF was in use by teachers, the framework acted as an appropriate tool in enhancing teachers' effectiveness in their everyday work despite the challenges they faced. During class observations, it was realised that teachers were guided by the PCF to select learning activities and plan for their lessons. This was learnt upon studying the schemes of work and the lesson plans of T3. It was evident that she had planned her lessons according to the scheme of work set out in the PCF, a role believed could be achieved by a qualified teacher who is either new or on the job training.

What came as a surprise was the teaching methodologies in place that the teacher applied, which appeared to have lacked play activities. However, with a single lesson observation, caution must be applied, as the findings might not be wholly dependable. This led the authors to interrogate the teachers' level of satisfaction in terms of training. During the interviews, some teachers voiced a concern that even though they had received pre-service training, they felt in-service training was insufficient and they faced some challenges in addressing some learning areas whilst teaching. Some of the learning areas that were cited by $\mathrm{T} 2$ were the spiritual, moral and reading perspectives. Unfortunately, these topics could not be observed as they had already been covered by the time the study was undertaken, causing us to depend solely on the teachers' opinions. Possibility of bias in these responses could be suggested. It is important to note that this study was carried out a year after the in-service workshop was conducted, implying that the challenges occurred even after the teachers were trained. 
A follow-up class observation was conducted to interrogate the teachers' level of training. In one class that was observed at S2, it appeared that T2 applied the lecture method during her lesson. The topic was about 'body parts' and a chart was used to engage the children in discussions. Some children seemed to be challenged with naming the specified body parts and the teacher helped them by telling them the correct answers. Afterwards, the children were directed and assisted in singing a song (Heads and Shoulders) regarding what had been learnt. The observation confirmed what the teachers had raised about insufficient in-service training. An assumption was made that the in-service training conducted in the region might have been misdirected. This is because the PEO had suggested that, 'we look at the curriculum framework and say these are the most important things that we can assist teachers on', signalling that they did not consult teachers when creating content for training. Upon studying the contents of the workshop, it was found that some of its details appeared to be congested. Issues of lesson, scheming and special needs were to be addressed. What became somewhat interesting was when the term 'curriculum' was mentioned as part of the content that teachers were to be trained on. Based on Wood and Hedges' (2016) argument, it is common to find some people regarding that curriculum refers to the learning contents, methodologies and how individuals apply their unique skills and values in dispensing the curriculum. This is believed as being superficial, and Wood and Hedges (2016) emphasised that although the latter might be true, these are influenced by different contextual backgrounds of politics, socio-economic and personal issues. So, when the PEO suggested that they chose the content to train teachers on, they can be assumed as having applied their personal judgement, hence a suggestion that training may have been misdirected.

In ECD, children learn best through self-initiated, interactive and stimulating activities as suggested by Hollowell et al. (2019). This denotes a process whereby children would independently establish what is expected from them and the teacher would facilitate learning through providing an enabling environment. This would include providing relevant resources and directing and monitoring that all activities are correctly implemented. The teacher would also be engaged through assisting those children experiencing challenges and recording progress. This process is what is referred to as formative assessment. In this particular case, the teacher appeared as the main director of activities, which as Hollowell et al. (2019) suggested involves the teacher giving children instructions and modelling and is not beneficial at the ECD stage as children learn best through self-initiated learning with the teacher providing assistance. Figure 1 is an illustration of the seating arrangements during the lesson observed where teacher-centred approach seemed to dominate. The BPCF advocates for child-centred activities that promote children towards being creative through discovering and manipulating objects (DCDE 2012a).

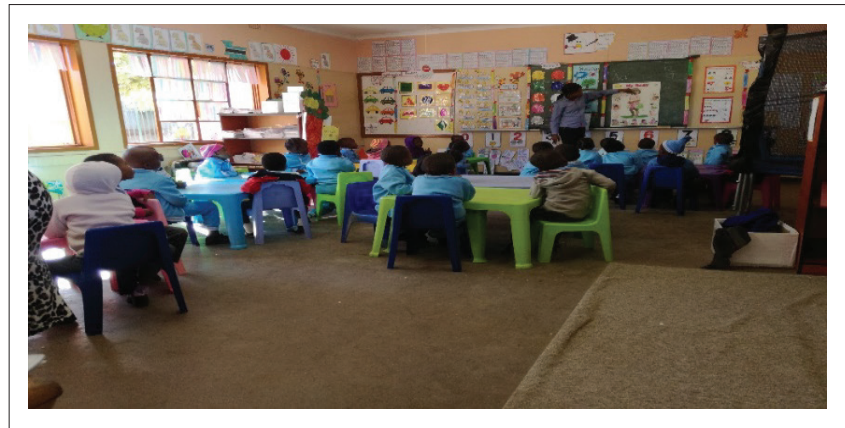

Photograph taken by researcher during the classroom observations, school 2, date unspecified, Francistown.

FIGURE 1: Sample of classroom seating.

In discussing this with the teacher, she reported that she often faced challenges in addressing some topics because of failure to interpret some objectives and would sometimes resort to leading the activities. Although there appeared to have been an exclusion of play activities, these results should be interpreted with caution because some studies have shown that a mix of child and teacher-led activities proved to engender positive learning outcomes. As shown previously, the PCF advocates for child-centred approach pedagogies. This is assumed to mean that the teacher should not be the source of all learning, but rather direct activities geared towards leaning. Considering the observed topic, one would have suggested for more and diverse engaging activities to reinforce the key concepts as the DCDE (2012b) proposed. For instance, the teacher could have invited children to draw and colour the person and label the different body parts, then at the end, they could discuss their discoveries with the teacher.

The given findings led to further enquiry with the school principals on their role and input regarding the challenges faced by teachers in implementing the PCF. Interestingly, P1 and P2 reported being satisfied with teachers' level of pre-service training as they reported that the REO was responsible for hiring trained teachers. This was accepted as credible because in Botswana, with the introduction of public pre-primary schools, the government ventured into at least initial training of ECD teachers through different institutions such as Ba Isago University College, Botswana Open University and some colleges of education (MOESD 2015b). The teachers confirmed this when they mentioned their qualifications. One inconsistency that appeared to deter teachers' effectiveness in implementing the PCF was inadequate in-service PD workshops especially that the PCF is a newly introduced policy.

Further probing disclosed that the SPs were not professionally trained on the implementation of the PCF. Two out of three teachers alluded to the fact that their supervisors were not able to assist them in terms of in-service training as they were not familiar with the subject matter. The same sentiments were shared by the SPs themselves, proving that indeed if they were not inducted into the programme, it would be challenging to effectively help the teachers. This inconsistency caused the authors to challenge the internal support systems 
as espoused by the SCLT and CoP theories because supervisors, as part of the school, need to at least be informed about the job they supervise to effectively assist their supervisees as part of training on the job.

\section{Reflections on the successes and challenges faced by teachers' training in implementing the pre-primary curriculum framework}

The question focused on teachers' successes and challenges in implementing the PCF. Despite what seemed like insufficient training on the part of teachers, they reported positive achievement on implementation of the PCF within their classes. P2 reported that, from an outward impression, teachers seemed to enjoy implementing the framework. She reported this view based on her observation of how teachers interacted with the children. This was confirmed by T1 who reported that she liked working with the PCF as it acted as a guide in her daily teaching. T2 reiterated the fact that the PCF was an improvement on the previous one and it made their work easier as it had clear objectives and suggested activities and teaching materials for the lessons to be conducted. Upon interrogating the PCF document, it was realised that indeed it contained information relating to all the learning areas, objectives and key concepts that children were expected to learn. It also gave teachers ideas on how they could assist with developing children's competency levels. For example, within each learning area, the outcomes are subdivided into various competency levels to enable tracking of each child's performance either through talking, performing or behaving in different ways. To add to achieving all these milestones, learning materials are also stipulated as a guide to the relevant methodologies to employ.

Regarding challenges, teachers raised several challenges that ranged from socio-economic and environmental to political. Some of the socio-economic challenges consisted of a shortage of funds from both the government and parents in assisting teachers with teaching resources. Environmental impediments were mentioned as lack of developed space suitable for children's outdoor teaching and play areas. It was observed that in almost all the schools there was little space demarcated for outdoor activities. The principals explained that the reception classes had been established within primary schools, which prevented schools from creating space for play areas. These reasons were unconvincing as there was space available and it was the mandate of each school to develop the spaces for outdoor activities.

With regard to political challenges, participants outlined a lack of appropriate supervision at school level as a factor that impacted their PD. One of the teacher participants, T2, raised a concern that her immediate supervisor was not trained in ECD and was therefore limited in assisting them on issues relating to curriculum implementation. This was confirmed by both the SPs and PEOs. The PEOs indicated that they were not familiar with the ECD curriculum but were requested to 'babysit' the department. Upon enquiring on how they assisted teachers on PD issues, the PEO indicated that they engaged external trainers. What was interesting was that it was the same PEOs who suggested the content teachers were to be trained on. This was confirmed when the PEO reported that they sat down and chose the topics, which they considered would be problematic to teachers. Other strategies of the PEOs were the use of social media and school fairs for teachers to connect and share issues relating to how they could implement the PCF and was appreciated as a component appealing to the SCLT and CoP perspective.

\section{Views of teachers on support offered towards promoting effective pre-primary curriculum framework implementation}

Even though teachers reported success in implementing the PCF in Francistown, Botswana, they were faced with some challenges as well. During the interviews with almost all the participants, it became apparent that teachers' challenges were addressed both internally and externally. Most teachers indicated that, despite the shortage of resources, they were able to improvise through making the resources they needed, and in some cases, they sacrificed money from their own pockets or they were assisted by parents through pledges. This was emphasised by P1 and the PEO who indicated that teachers were advised to engage with parents on issues relating to the shortage of resources.

\section{Study's limitations}

This study was conducted within one specific area being the City of Francistown, but different locations were visited. This impacted the number of participants because it was limited to only three schools, three teachers, two SPs, one PEO and one PES. As a result, this narrowed the scope and transferability of the study's findings. This denotes that other pre-primary school settings may provide different experiences; hence, it may prove challenging to generalise. However, the recommendations made may be applied to other regions.

Another limitation of this study was that within the chosen study samples, there was an observable disparity in terms of age and gender of participants. All the three teachers were females and had age ranges of 28, 30, and 39. Regarding the SPs, one was male and another was female, and their ages were 45 and 56, respectively. The PEO and PES were male and female, respectively, and fell within the same age category of 52 and 53 . These unique combinations could be different in other locations; hence the findings could not be generalised.

\section{Implications}

The study is intended for all ECD practitioners in the teaching fraternity, supervisors and trainers dealing with the development and implementation of the PCF. In Botswana, as part of promoting children's holistic development, an integrated PCF was introduced and all government 
pre-primary schools are expected to follow it. From the evidence gathered, it was learnt that teachers applied the PCF but were faced with some challenges in the form of inadequate in-service training, learning resources and supervision. During the discussion of the three themes that emerged, it was realised that amongst other things, teachers needed ongoing and routine PD, effective supervisory initiatives, relevant teaching and learning materials, and parental support to be effective in implementing the PCF.

This study augments the perspectives of those who value inservice training, availing learning resources and instructional leadership as determining factors towards promoting teachers' effectiveness in implementing the PCF. Some people may overlook these valued principles and suffer the consequences of having a teaching workforce that may lack focus on what would be expected from them because of inadequate policy direction. Policy direction on PD training strategies would influence both teachers and their supervisors to better implement the PCF. This is because teachers would be empowered to come up with relevant teaching strategies and resource utilisation and improvisation would be easier as these would be some of the content to focus on. Supervisors, both at school and regional level, would have a clear direction relating to how best to assist their supervisees.

\section{Recommendations}

From the evidence gathered by this study, it was learnt that teachers applied the Botswana's PCF. During the discussion of the themes that emerged, it was realised that amongst other things, teachers needed PD, relevant teaching and learning materials, and instructional leadership to be effective in implementing the PCF. The findings also present a need to reflect on the importance of implementing the PCF to promote teachers' effectiveness and holistic development of children. The study recommends the establishment of specific and intensified training protocols for teachers. This would entail providing clear guidelines on how to approach the different learning areas and routine provision and inspection of available teaching and learning resources by the relevant authorities. This is because there are some inconsistencies in the implementation of the PCF as observed. There should also be clear and consistent operational coordination between the two departments of MoBE and MLGRD for effectiveness in directing the implementation of the PCF.

Further research supporting the impact of in-service training, instructional leadership, and teaching and learning resources provision on effective implementation of the PCF could be helpful to the two ministries that pre-primary education falls under. A study that is suggested could be extended to other parts of the region and country and even delve into the concepts of the PCF such as how the unique learning areas such as literacy skills can be addressed. When the policymakers recognise the impact of training, availing of resources and effective leadership towards the PCF, teachers would be able to develop and promote the children's expected skills as enshrined in the PCF.

\section{Conclusion}

The study aimed at investigating the role of teacher training in promoting teachers' effectiveness in implementing the PCF in Francistown, Botswana, arguing from Bandura's (1971) SCLT and Wenger and Wenger-Trayner's (2015) CoP theories. From the findings, it was evident that ECD teachers in the three visited schools appreciated the policy stipulated by MoBE to implement the PCF in their daily teaching and learning activities. The experiences of the ECD practitioners revealed both successes and challenges although the successes seemed to outweigh the challenges because of the high level of teacher commitment to the initiative. Another observation made was teachers' open-mindedness and creativity, which enabled them to work effectively regardless of the challenges they faced. Lastly, this article argues that infusing Bandura and Wenger's theoretical frameworks into ECD training and curriculum implementation would provide an enabling environment for teachers.

\section{Acknowledgements}

The authors would like to acknowledge Prof. Nkidi Phatudi for giving some advice at the beginning of this research.

\section{Competing interests}

The authors declare that they have no financial or personal relationships that may have inappropriately influenced them in writing this article.

\section{Authors' contributions}

E.L.B. and R.S.S.M. contributed equally to this research article.

\section{Funding information}

This research received no specific grant from any funding agency in the public, commercial or not-for-profit sectors.

\section{Data availability}

The data that support the findings of this study are available from the corresponding author, R.S.S.M., upon reasonable request.

\section{Disclaimer}

The views and opinions expressed in this article are those of the authors and do not necessarily reflect the official policy or position of any affiliated agency of the authors.

\section{References}

Abreh, M.K., 2018, 'Heads of departments' perception of teachers' participation in continuous professional development programmes and its influence on science and mathematics teaching in Ghanaian secondary schools', African Journal of Educational Studies in Mathematics and Sciences 14(2018), 85-99.

Abroampa, W.K., 2018, 'Assessment of kindergarten teachers' use of learning activities and instructional resources in the implementation of the curriculum in Central Region, Ghana', International Journal of Innovative Research and Development 7(6), 67-73. https://doi.org/10.24940/ijird/2018/v7/i6/ and Developr 
Aiono, S., McLaughlin, T. \& Riley, T., 2019, 'While they play, what should I do? Strengthening learning through play and intentional teaching', He Kupu 6(2), 59-68, viewed n.d., from https://www.hekupu.ac.nz/sites/default/files/201959-68, viewed n.d., from https://www.hekupu.ac.
10/11\%20Aiono\%20McLaughlin\%20and\%20Riley.pdf.

Alase, A., 2017, 'The interpretative phenomenological analysis (IPA): A guide to a good qualitative research approach', International Journal of Education and Literacy Studies 5(2), 9-19. https://doi.org/10.7575/aiac.ijels.v.5n.2p.9

Aljarrah, A., 2017, 'Play as a manifestation of children's imagination and creativity', Journal for the Education of Gifted Young Scientists 5(1), 23-36. https://doi. org/10.17478/10.17478/JEGYS.2017.52

Bandura, A., 1971, Social learning theory, General Learning Press, New York, NY, viewed 04 October 2018, from http://www.asecib.ase.ro/mps/Bandura SocialLearningTheory.pdf.

Bandura, A., 1994, 'Self-efficacy', in V.S. Ramachaudran (ed.), Encyclopedia of human behavior, vol. 4, pp. 71-81, Academic Press, New York, NY. https://doi.org/ 10.1016/B978-0-08-097086-8.25033-2

Bellibas, M. \& Liu, Y., 2017, 'Multilevel analysis of the relationship between principals' perceived practices of instructional leadership and teachers' self-efficacy perceptions', Journal of Educational Administration 55(1), 49-69. https://doi. org/10.1108/JEA-12-2015-0116

Black, F.V., 2019, 'Collaborative inquiry as an authentic form of professional development for preschool practitioners', Educational Action Research 27(2), 227-247. https://doi.org/10.1080/09650792.2018.1452770

Botswana National Commission for UNESCO, 2018, Botswana National Implementation Plan For Sustainable Development Goal (SDG) 4- Education 2030, Ministry of Plan For Sustainable Development Goal (SDG) 4- Education 2030 .
Tertiary Education, Research, Science and Technology, Gaborone.

City of Francistown Council, 2018, 2017/2018 orders for preschool furniture, s.n., Francistown.

Clark, K., 2020, 'Play-based early childhood curriculum and early literacy success link', Master's thesis, Northwestern College.

Darling-Hammond, L., 2017, 'Teacher education around the world: What can we learn from international practice?', European Journal of Teacher Education 40(3) 291-309. https://doi.org/10.1080/02619768.2017.1315399

Darling-Hammond, L., Hyler, M.E. \& Gardner, M., 2017, Effective teacher professional development, Learning Policy Institute, Palo Alo, CA.

Department of Curriculum Development and Evaluation (DCDE), 2012, Pre-primary curriculum framework, DCDE, Gaborone.

Department of Curriculum Development and Evaluation (DCDE), 2012, Pre-primary curriculum teacher's handbook: Curriculum Development and Evaluation, DCDE, Gaborone.

Dossett, J., Stripling, C.T., Haynes, J.C., Stephens, C.A. \& Boyer, C., 2019, 'Mathematics efficacy and professional development needs of Tennessee agricultural education teachers', Journal of Agricultural Education 60(4), 255-271. https://doi.org/ 10.5032/jae.2019.04255

Du Plessis, P. \& Mestry, R., 2019, 'Teachers for rural schools - A challenge for South Africa', South African Journal of Education 39(September), 1-9. https://doi.org/ 10.15700/saje.v39ns1a1774

Farnsworth, V., Kleanthous, I. \& Wenger-Trayner, E., 2016, 'Communities of practice as a social theory of learning: A conversation with Etienne Wenger', British Journa of Educational Studies 64(2), 139-160. https://doi.org/10.1080/00071005.2015. 1133799

Hivner, E.A., Hoke, A.M., Francis, E.B., Lehman, E.B., Hwang, G.W., Kraschnewski, J.L., 2019, 'Training teachers to implement physical activity: Applying social cognitive theory', Health Education Journal 78(4), 464-475. https://doi.org/10.1177/ 0017896918820558

Hollowell, J., Dumbaugh, M., Belem, M., Kousse, S., Swigart, T., Korsaga, C. et al., 2019 "'Grandmother, aren't you going to sing for us?" Current childcare practices and caregivers' perceptions of and receptivity to early childhood development activities in rural Burkina Faso', BMJ Global Health, 1-10. https://doi.org/10.1136/ activities in rural Burkin
bmjgh-2018-001233

Kennedy, M.M., 2016, 'How does professional development improve teaching?', Review of Educational Research 86(4), 945-980. https://doi.org/10.3102/0034654315626800

Lam, B.H. \& Tsui, K.T., 2014, 'Curriculum mapping as deliberation - Examining the alignment of subject learning outcomes and course curricula', Studies in Higher Education 41(8), 1-18. https://doi.org/10.1080/03075079.2014.968539

Lombard, M., Snyder-Duch, J. \& Bracken, C.C., 2002, 'Content analysis in mass communication: Assessment and reporting of intercoder reliability', Human Communication Research 28(4), 587-604. https://doi.org/10.1093/hcr/28.4.587

Lopez, P., 2018, Learning through play: Strengthening learning through play in early childhood education programmes, UNICEF, New York, NY.

Mavidou, A. \& Kakana, D., 2019, 'Teachers' experiences of a professional development program for differentiated instruction', Creative Education 10(03), 555-569. https://doi.org/10.4236/ce.2019.103040

Ministry of Education and Skills Development (MOESD), 2012, Pre-primary curriculum framework, Ministry of Education and Skills Development, Gaborone.

Ministry of Education and Skillls Development (MOESD), 2015a, Botswana education and training sector strategic plan (ETSSP 2015-2020), Department of Curriculum Development and Evaluation, Gaborone.

Ministry of Education and Skills Development (MOESD), 2015b, Specifications guidelines for pre-primary education learning support resources, Department of Curriculum Development and Evaluation, Gaborone.
Morrison, J.W., Story, P. \& Zhang, I., 2015, 'Accessible family involvement in early childhood programs', Southern Early Childhood Association, 43(1), 21-26.

Mphahlele, R.S.S., 2018, 'Information communication technologies as a aupport mechanism for learners experiencing reading difficulties in full-service schools', PhD thesis, University of South Africa.

Nel, N., Mohangi, K., Krog, S. \& Stephens, O., 2016, 'An overview of grade R literacy teaching and learning in South Africa', PerLinguam 32(2), 47-65. https://doi. org/10.5785/32-2-651

Omaga, J.F. \& Alieto, E.O., 2019, 'Teaching literacy through play: Perspective from Filipino early childhood teachers', Online Submission 31(3), 477-481.

Ozkan, H.H., 2016, 'The analysis of the opinions of school directors about their knowledge of the curriculums and their support and control in the implementation' Universal Journal of Educational Research 4(11), 2656-2668. https://doi. org/10.13189/ujer.2016.041120

Pianta, R., Downer, J. \& Hamre, B., 2016, 'Quality in early education classrooms: Definitions, gaps, and systems', Future of Children 26(2), 119-138. https://doi org/10.1353/foc.2016.0015

Piasta, S.B., Logan, J.A.R., Pelatti, C.Y., Capps, J.L. \& Petrill, S.A., 2015, 'Professiona development for early childhood educators: Efforts to improve math and science learning opportunities in early childhood classrooms', Journal of Educational Psychology 107(2), 407-422. https://doi.org/10.1037/a0037621

Porter, T., West, M.E., Kajfez, R.L., Malone, K.L. \& Irving, K.E., 2019, 'The effect of teacher professional development on implementing engineering in elementary schools', Journal of Pre-College Engineering Education Research 9(2), 64-71. https://doi.org/10.7771/2157-9288.1246

Pyle, A., Prioletta, J. \& Poliszczuk, D., 2018, 'The play-literacy interface in full-day kindergarten classrooms', Early Childhood Education Journal 46(1), 117-127. https://doi.org/10.1007/s10643-017-0852-z

Sarikaya, N. \& Erdogan, C., 2016, 'Relationship between the instructional leadership behaviors of high school principals and teachers' organizational commitment', Journal of Education and Practice 7(3), 72-82.

Schachter, R.E., Gerde, H.K. \& Hatton-Bowers, H., 2019, 'Guidelines for selecting professional development for early childhood teachers', Early Childhood Education Journal 47(4), 95-408. https://doi.org/10.1007/s10643-019-00942-8

Shabani, K., 2016, 'Applications of Vygotsky's sociocultural approach for teachers' professional development', Cogent Education 3(1), 1-10. https://doi.org/10.1080 /2331186X.2016.1252177

Sutton, J. \& Austin, Z., 2015, 'Qualitative research: Data collection, analysis, and management', The Canadian Journal of Hospital Pharmacy 68(3), 226-231. https://doi.org/10.4212/cjhp.v68i3.1456

The World Bank, 2019, Public expenditure review of the basic education sector in Botswana, The International Bank for Reconstruction and Development, Washington, DC

Tredoux, C. \& Smith, M., 2010, 'Evaluating research design', in M. Terre Blanche, K. Durrheim \& D. Painter (eds.), Research in practice; Applied methods in the socia sciences, 2nd edn., pp. 161-186, Cape Town Press, Cape Town.

Tuffour, I., 2017, 'A critical overview of interpretative phenomenological analysis: A contemporary qualitative research approach', Journal of Healthcare Communications 2(4), 1-5. https://doi.org/10.4172/2472-1654.100093

Úcar, X., 2013, 'Exploring different perspectives of social pedagogy: Towards a complex and integrated approach', Education Policy Analysis Archives 36(21), 1-19. https:// doi.org/10.14507/epaa.v21n36.2013

United Nations Children's Fund (UNICEF), 2019, A world ready to learn: Prioritizing quality early childhood education, New York, NY, viewed 30 September 2020, from https://www.unicef.org/media/57926/file/Aworld-ready-to-learn-advocacybrief-2019.pdf.

United Nations Educational, Scientific and Cultural Organization (UNESCO), 2015, Early childhood development Kit handbook, 1st edn., United Nations Educational,
Scientific and Cultural Organisation, Copenhagen, viewed 15 July 2019, from Scientific and Cultural Organisation, Copenhagen, viewed 15 July 2019, from
https://www.unicef.org/supply/files/Education_Kits_User_Manuals_Module_3. pdf.

Vrieling, E., Van den Beemt, A. \& De Laat, M., 2016, 'What's in a name: Dimensions of social learning in teacher groups', Teachers and Teaching: Theory and Practice 22(3), 273-292. https://doi.org/10.1080/13540602.2015.1058588

Wenger, E. \& Wenger-Trayner, B., 2015, Communities of practice: A brief introduction viewed $\mathrm{n}$ d from https://wenger-trayner.com/wp-content/uploads/2015/04/07Brief-introduction-to-communities-of-practice.pdf.

Wood, E. \& Hedges, H., 2016, 'Curriculum in early childhood education: Critical questions about content, coherence, and control', Curriculum Journal 27(3), 387-405. https://doi.org/10.1080/09585176.2015.1129981

Yılmaz, A. \& Pala, Ş., 2019, 'Opinions related to play concept of children in early childhood', Pegem Egitim ve Ögretim Dergisi 9(3), 945-978. https://doi. org/10.14527/pegegog.2019.030

Yüksel, P. \& Yıldırım, S., 2015, 'Theoretical frameworks, methods, and procedures for conducting phenomenological studies in educational settings', Turkish Online Journal of Qualitative Inquiry 6(1), 1-20. https://dergipark.org.tr/tr/download/ article-file/199867

Zahnd, W.E., Smith, T., Ryherd, S.J., Cleer, M., Rogers, V. \& Steward, D.E., 2017 'Implementing a nutrition and physical activity curriculum in Head Start through an academic-community partnership', Journal of School Health 87(6), 465-473. https://doi.org/10.1111/josh.12515 